\title{
Central metabolic messengers and the effects of nutrition on gonadotrophin secretion in sheep
}

\author{
D. W. Miller ${ }^{1 *}$, D. Blache ${ }^{1}$, R. Boukhliq ${ }^{1 \dagger}$, J. D. Curlewis ${ }^{2}$ and \\ G. B. Martin ${ }^{1,3}$ \\ ${ }^{1}$ Faculty of Agriculture (Animal Science), University of Western Australia, Nedlands 6907, Western \\ Australia, Australia; ${ }^{2}$ Department of Physiology and Pharmacology, University of Queensland, Queensland \\ 4072, Australia; ${ }^{3}$ CSIRO Division of Animal Production, Private Bag, Wembley 6014, Western Australia, \\ Australia
}

\begin{abstract}
Nutrition influences the reproductive axis via alteration of gonadotrophin secretion. However, a link between nutrition and the secretion of $\mathrm{GnRH}$, which drives the axis, has yet to be established. The aim of the present study was to measure the change in the concentrations of metabolic substances in the cerebrospinal fluid of adult male sheep offered a diet designed to maintain constant gonadotrophin secretion (Group $\mathrm{M} ; n=6$ ), or a diet known to increase gonadotrophin secretion (Group $M+L ; n=6$ ). On days 1,3 and 10 of the dietary treatments, cerebrospinal fluid and jugular blood were sampled and analysed for metabolic fuels (glucose, amino acids and free fatty acids) and metabolic hormones (insulin, insulin-like growth factor I, GH, prolactin, cortisol and the thyroid hormones). On day 11 of the dietary treatment, LH pulse frequency and mean FSH concentrations in Group $\mathrm{M}+\mathrm{L}$ had increased relative to Group $M$ and to day 0 . Plasma concentrations of prolactin and insulin on days 3 and 10, and glucose and insulin-like growth factor I on day 10, were higher in Group $M+L$ than in Group $M$, but only cerebrospinal fluid concentrations of insulin, glucose and certain amino acids were affected by the dietary treatments on days 3 and 10. Cerebrospinal fluid, but not plasma, concentrations of aspartate, tyrosine, cystine, phenylalanine and arginine on day 3 , and glutamine, $\gamma$-aminobutyric acid, threonine, alanine on days 3 and 10, were higher in Group M + L relative to Group M. On day 10, plasma and cerebrospinal fluid concentrations of arginine, phenylalanine, proline, tyrosine, methionine and phosphoserine, but only the plasma concentrations of linoleic acid, aspartate and serine, were higher in Group $\mathrm{M}+\mathrm{L}$ than in Group $\mathrm{M}$. Concentrations of triiodothyronine, thyroxine, and cortisol in plasma and cerebrospinal fluid were not affected. These results show that the nutritional stimulation of gonadotrophin secretion is accompanied primarily by fluctuations in plasma and cerebrospinal fluid concentrations of insulin and certain amino acids, which suggests that, when nutritional status is improved, insulin, amino acids and possibly glucose interact to modulate $\mathrm{GnRH}$ secretion.
\end{abstract}

\section{Introduction}

The development and function of the reproductive organs are dependent on circulating concentrations of $\mathrm{LH}$ and $\mathrm{FSH}$, which are controlled by the network of neurones in the hypothalamus that produce GnRH. Environmental factors, such as nutrition, that influence gonadal activity are thought to act primarily at the hypothalamus to alter the secretion of GnRH. Certainly, there is a strong correlation between gonadotrophin concentrations, the onset of puberty and metabolic status in humans,

\footnotetext{
*Present address: Department of Agriculture, University of Aberdeen, 581 King St, Aberdeen AB24 5UA, UK.

'Present address: Department of Physiology, Health Sciences Center, West Virginia University, PO Box 9229, Morgantown, WV 26506-9229, USA. Received 14 July 1997.
}

monkeys, rats and sheep (Cameron et al., 1985; Foster and Olster, 1985; Sisk and Bronson, 1986; Williams and Cameron, 1996), suggesting that the $\mathrm{GnRH}$ pulse generator must have some way of sensing the metabolic status of the animal. One possibility is that circulating metabolic fuels and metabolic hormones relay messages about the nutritional status of the animal to the GnRH-producing cells. A valuable first step in examining the putative role of metabolic signals as a link between nutrition and the stimulation of the GnRH pulse generator would be to measure the concentrations of metabolic fuels (glucose, amino acids and free fatty acids) and metabolic hormones (insulin, insulin-like growth factor I (IGF-I), GH, prolactin, cortisol and the thyroid hormones) in cerebrospinal fluid (CSF) near areas of the central nervous system that are associated with the control of GnRH release. 
Mature male sheep were used as a model for studies into nutritional effects on the reproductive axis because their diets can be strictly controlled, their endocrine pattern is similar to that of humans, and the reproductive system, including gonadotrophin secretion, can be reliably stimulated by nutritional supplementation (for review see Martin et al., 1994). In addition, sampling of CSF for metabolic perturbations is not feasible in humans, rats or monkeys because of the volume needed for accurate analysis of several substances and the cost. The aim of the present study was to measure the concentrations of metabolic fuels and metabolic hormones in areas of the central nervous system associated with the control of $\mathrm{GnRH}$ release in adult male sheep that had been offered diets that either stimulated or maintained gonadotrophin secretion. The hypothesis tested was that nutrition-related fluctuations in the peripheral concentrations of metabolic substances are detectable in areas of the brain associated with the control of $\mathrm{GnRH}$ secretion.

\section{Materials and Methods}

In December (early breeding season), twelve intact, Poll Merino rams ( 3 years old and with an average liveweight of $67 \pm 1.0 \mathrm{~kg}$ ) were placed in individual pens in an animal house at the University of Western Australia with natural lighting (at latitude $31^{\circ} 56^{\prime} \mathrm{S}$, the range is $10 \mathrm{~h}$ light: $14 \mathrm{~h}$ dark in winter to $14 \mathrm{~h}$ light:10 $\mathrm{h}$ dark in summer). They were then acclimatized to a roughage-based diet designed to maintain constant bodyweight (McDonald et al., 1991) that comprised a mixture of oaten chaff, mineral supplement (Siromin: Narrogin Mineral Stockmix; Narrogin, WA) and lupin grain (Lupinus angustifolius c.v. Uniwhite) in the ratio of 87:3:10 (lupin grain provides high amounts of digestible energy and protein, similar to soya bean).

The lateral cerebral ventricles were cannulated, as described by Forbes (1974). Animals were deprived of food and water for $24 \mathrm{~h}$ before surgery, initially anaesthetized with $20 \mathrm{ml}$ (i.v.) of $5 \%$ thiopentone sodium BP (Bomothal; Bomac Laboratories Pty Ltd, Sydney) and then maintained under general anaesthesia with $2-3 \%$ halothane Ph.Eur. (Fluothane; ICI, Sydney) in oxygen at $500 \mathrm{ml} \mathrm{min}^{-1}$ after tracheal intubation. After surgery, $5 \mathrm{ml}$ (i.m.) of penicillin and streptomycin antibiotic (Pen and Strep; Heriot Agvet, Melbourne) and $4 \mathrm{ml}$ (i.v.) of gentamicin (Gentapex-5; Apex Laboratories, Perth) were administered daily for 1 week.

The sheep were allowed a postoperative recovery period of at least 3 weeks, after which they were divided into two equal groups ( $n=6$ ) so that bodyweight, body condition score and testicular size were equal between the groups. One group remained on the maintenance diet (Group M) while the other was offered the maintenance diet plus a daily supplement of $750 \mathrm{~g}$ lupin grain for 10 days (Group $\mathrm{M}+\mathrm{L}$ ) providing about 2.5 times the maintenance energy requirement (Petterson and Mackintosh, 1994). Blood (3 ml) was sampled via indwelling jugular catheters every $20 \mathrm{~min}$ for $24 \mathrm{~h}$ before the start (day 0 ) and at the end of the supplementary feeding period (day 11) for gonadotrophin analysis. On days 1,3 and 10 , blood $(5 \mathrm{ml})$ and CSF $(0.5-1.0 \mathrm{ml})$ were sampled every $6 \mathrm{~h}$, starting $2 \mathrm{~h}$ before feeding, for $24 \mathrm{~h}$. The CSF samples were obtained from conscious, unrestrained animals by inserting a sterile 19-gauge needle down either of the two guide cannulae to an approximate depth that corresponded to the ependymal lining of the lateral ventricle. Slight suction pressure was then applied with a $1 \mathrm{ml}$ syringe attached to the sampling needle as the ependymal lining was punctured. This technique permits natural closure of the system during intervals between CSF sampling (Pappenheimer et al., 1962). The plasma and CSF samples collected every $6 \mathrm{~h}$ on days 1,3 and 10 were pooled by day for glucose, amino acids, free fatty acids, insulin, IGF-I, GH, prolactin, cortisol and thyroid hormone concentrations. Centrifugation was not carried out on the CSF samples as microscopic investigation revealed that the method used to collect the CSF did not result in significant contamination with red blood cells.

\section{Hormone and metabolite assays}

Plasma LH was measured in duplicate by a double-antibody radioimmunoassay (Martin et al., 1980). The ovine LH (CNRSM3; biopotency 1.8 iu NIH-LH-SI $\mathrm{mg}^{-1}$ ) used for iodination and standards was kindly supplied by M. Jutisz (College de France, Paris). Samples were assayed in duplicate $200 \mu \mathrm{l}$ aliquots and the limit of detection was $0.24 \pm 0.05 \mathrm{ng} \mathrm{ml}^{-1}$ (mean \pm SEM). The intra-assay coefficient of variation was estimated in each assay using six replicates of three control samples containing $0.27(8.3 \pm 2.3 \%), 1.4(10.9 \pm 3.6 \%)$ and 7.7 $(9.8 \pm 2.1 \%) \mathrm{ng} \mathrm{ml}^{-1}$. The interassay coefficients of variation were $9.8 \%, 10.2 \%$ and $14.3 \%$, respectively. The effect that this would have had on the detection of LH pulses was avoided by assaying all samples from one animal in the same run.

Plasma FSH was measured in duplicate by a double-antibody radioimmunoassay (Atkinson and Adams, 1988) using NIAMDD-oFSH-RP-I (biopotency $75 \times$ NIH-FSH-SI) and NIDDK-anti-oFSH-1 serum. The samples were assayed as duplicate $100 \mu \mathrm{l}$ aliquots and the limit of detection was $0.11 \mathrm{ng}$ $\mathrm{ml}^{-1}$. Six replicates of three control samples containing $0.7,4.3$ and $6.5 \mathrm{ng} \mathrm{FSH} \mathrm{ml}^{-1}$ were included in the assay and were used to estimate the intra-assay coefficients of variation $(4.6 \pm 0.9$, $10.8 \pm 1.5$ and $11.0 \pm 2.1 \%$, respectively).

Glucose concentrations in plasma and CSF were measured in duplicate by the glucose oxidase method (Bergmeyer and Bern't, 1974). Samples were deproteinized and assayed as duplicate $20 \mu \mathrm{l}$ aliquots and the limit of detection was $0.1 \mathrm{mmol} 1^{-1}$. Six replicates of two control samples containing 3.1 and 6.1 mmol glucose $1^{-1}$ were included in the assay and were used to estimate the intra-assay coefficients of variation (1.4 \pm 0.1 and $1.4 \pm 0.1 \%$ ).

Insulin concentrations in plasma and CSF were measured in duplicate by double-antibody radioimmunoassay (Tindal et al., 1978). The samples were assayed as duplicate $200 \mu \mathrm{l}$ aliquots and the limit of detection was $0.01 \mathrm{ng} \mathrm{ml}^{-1}$. Six replicates of two control samples containing 0.1 and $0.8 \mathrm{ng}$ insulin $\mathrm{ml}^{-1}$ were included in the assay and were used to estimate the intra-assay coefficients of variation $(4.1 \pm 0.5$ and $11.2 \pm 2.2 \%$, respectively).

Concentrations of prolactin in plasma and CSF were measured in duplicate by a double-antibody homologous radioimmunoassay (Miller et al., 1995). The standard (NIDDKoPrl-I-2) and antiserum (R160) were kindly donated by 
J. A. Avenell (CSIRO Division of Animal Production, Prospect, NSW). The samples were assayed as duplicate $10 \mu \mathrm{l}$ (plasma) or $100 \mu \mathrm{l}$ (CSF) aliquots and the limit of detection was $0.66 \mathrm{ng}$ $\mathrm{ml}^{-1}$. Six replicates of two control samples containing 0.6 and $7.1 \mathrm{ng}$ prolactin $\mathrm{ml}^{-1}$ were included in the assay and were used to estimate the intra-assay coefficients of variation $(5.3 \pm 1.9$ and $10.4 \pm 0.9 \%)$.

Plasma and CSF concentrations of GH were measured in duplicate by the double-antibody radioimmunoassay (Downing et al., 1995). The samples were assayed as duplicate $100 \mu \mathrm{l}$ (plasma) or $200 \mu \mathrm{l}$ (CSF) aliquots and the limit of detection of the $\mathrm{GH}$ assay was $1.1 \mathrm{ng} \mathrm{ml} \mathrm{gl}^{-1}$. Six replicates of two control samples containing 22.6 and $43.2 \mathrm{ng} \mathrm{ml}^{-1}$ were included in the assay and were used to estimate the intra-assay coefficients of variation (7.2 \pm 1.22 and $10.4 \pm 0.85 \%$, respectively).

IGF-I concentrations in plasma and CSF were measured in duplicate by double-antibody radioimmunoassay (Gluckman et al., 1983). Interference by binding proteins was minimized by acid-ethanol cryoprecipitation, as validated for ruminant samples by Breier et al. (1991). The samples were assayed as duplicate $100 \mu \mathrm{l}$ aliquots and the limit of detection was $3.12 \mathrm{ng}$ $\mathrm{ml}^{-1}$. Six replicates of two control samples containing 7.7 and $27.7 \mathrm{ng}$ IGF-I ml ${ }^{-1}$ were included in the assay and were used to estimate the intra-assay coefficients of variation (13.4 \pm 2.54 and $11.5 \pm 1.84 \%$, respectively).

Concentrations of cortisol in plasma and CSF were measured in duplicate after extraction with methylene chloride:ethanol (99:1 v/v) using an radioimmunoassay based on separation with dextran-coated charcoal (Abraham et al., 1972). The samples were assayed as duplicate $100 \mu \mathrm{l}$ (plasma) or $150 \mu \mathrm{l}$ (CSF) aliquots and the limit of detection was $0.52 \mathrm{ng} \mathrm{ml}^{-1}$. Six replicates of three control samples containing 11.2, 23.6 and $34.3 \mathrm{ng}$ cortisol ml ${ }^{-1}$ were included in the assay and were used to estimate the intra-assay coefficients of variation $(10.1 \pm 2.80,12.0 \pm 4.50$ and $8.6 \pm 0.75 \%$, respectively).

Free tri-iodothyronine and thyroxine concentrations in plasma and CSF were measured using GammaCoat $\left.{ }^{(}{ }^{125} \mathrm{I}\right]$ kits (Incstar, Stillwater, MN). The samples for triiodothyronine were assayed as duplicate $50 \mu \mathrm{l}$ aliquots (limit of detection $0.50 \mathrm{ng} \mathrm{mI}^{-1}$ ) whereas those for thyroxine were assayed as duplicate $10 \mu \mathrm{l}$ (plasma) or $100 \mu \mathrm{l}$ (CSF) aliquots (limit of detection $7.8 \mathrm{ng} \mathrm{ml}^{-1}$ ). Six replicates of two control samples containing 1.6 and $4.0 \mathrm{ng} \mathrm{ml}^{-1}$ were included in the triiodothyronine assay and were used to estimate the intra-assay coefficients of variation (1.6 \pm 1.30 and $1.4 \pm 1.15 \%$, respectively). Six replicates of two control samples containing 0.41 and $1.43 \mu \mathrm{g} \mathrm{ml}^{-1}$ were included in the thyroxine assay and were used to estimate the intra-assay coefficients of variation ( $2.8 \pm 0.58$ and $3.5 \pm 0.95 \%$, respectively).

Fatty acid analysis of concentrations of palmitic, palmitoleic, stearic, oleic, linoleic, linolenic and arachidic acids in plasma and CSF was performed using a Hewlett-Packard $5890 \mathrm{~A}$ gas chromatograph equipped with a flame ionization detector. Samples were methylated by a one-step method using benzene and then chromatographed on an INNOWax capillary standard column $(20 \mathrm{~mm} \times 0.25 \mathrm{~mm}$ i.d. $\times 0.25 \mu \mathrm{m}$ film) (Sukhija and Palmquist, 1988). The limit of detection for each fatty acid was $2 \mathrm{ng} \mathrm{ml}^{-1}$ and the reproducibility of the procedure was $94 \%$.

Concentrations of amino acids: phosphoserine, aspartate, serine, glycine and asparagine, glutamine, taurine, $\gamma$-aminobutyric acid (GABA), threonine, alanine, arginine, proline, tyrosine, valine, methionine, cystine, isoleucine, leucine, phenylalanine, glutamate, histidine and tryptophan in plasma and CSF were determined using a Waters gradient HPLC system (Waters Assoc., Milford, MA) fitted with a UV detector $(254 \mathrm{~nm}, 0.05$ AUFS). Methionine sulfone was used as an internal standard. Samples were derivated and the separative and quantitative chromatographies were performed using a Waters reverse-phase C18 Pico-Tag $30 \mathrm{~cm} \times 3.9 \mathrm{~mm}$ i.d. stainless steel column as described previously (Cohen and Strydom, 1988; Robitaille and Hoffer, 1988). The limit of detection was $5 \mathrm{pmol} \mathrm{l}^{-1}$ for each amino acid and the coefficient of variation for each standard was $0.65 \%$.

\section{LH pulse analysis}

LH pulses were analysed using the 'Munro' pulse analysis program (Zaristow Software, West Morham, East Lothian). The baseline was calculated as a moving average over a $120 \mathrm{~min}$ window ( $60 \mathrm{~min}$ each side of the sample being tested). Individual peaks were tested against a threshold, where a pulse was accepted if the concentration at the peak exceeded the concentration at the previous nadir by $>1 \mathrm{SD}$, and the interval to the previous pulse was more than one sampling interval (that is, $>20 \mathrm{~min}$ ). Baxter parameters, describing the parabolic relationship between the concentrations of a hormone in the sample and the $\mathrm{SD}$, were derived from the precision in the quality controls for each assay by regressing the mean concentrations of the quality controls against their SD. The G parameters (the number of SD by which a peak must exceed the baseline in order to be accepted), GI to G5 were set at 3.0, 2.5, 1.9, 1.2 and $0.9 \mathrm{SD}$ for pulses containing 1 to 5 samples above baseline concentration, respectively.

\section{Statistical analyses}

One-way analysis of variance was used for comparisons between treatments with no time component. Data containing a time component were tested for time and treatment effects by repeated measures analysis of variance.

\section{Results}

There was no effect of the dietary treatments on bodyweight, body condition score or testicular size over the 11 days of the experiment (data not shown). On day 0 of the dietary treatments, there were no differences in gonadotrophin secretion between the two groups (Fig. 1). On day 11, LH pulse frequency and mean FSH concentrations had increased in the rams in Group $\mathrm{M}+\mathrm{L}$ relative to Group $\mathrm{M}$ and to day 0 $(P<0.05 ;$ Figs $I$ and 2$)$. The dietary treatments did not affect $\mathrm{LH}$ pulse amplitude, interpulse nadir or mean $\mathrm{LH}$ concentrations (Fig. 1).

The concentration of glucose in CSF was generally $25 \%$ less than in plasma. Repeated measures analysis revealed that there was no overall effect of dietary treatment, time or the interaction of dietary treatment and time on mean concentrations of glucose in plasma and CSF (Fig. 3). However, on day 10, glucose concentrations in plasma were higher in Group 

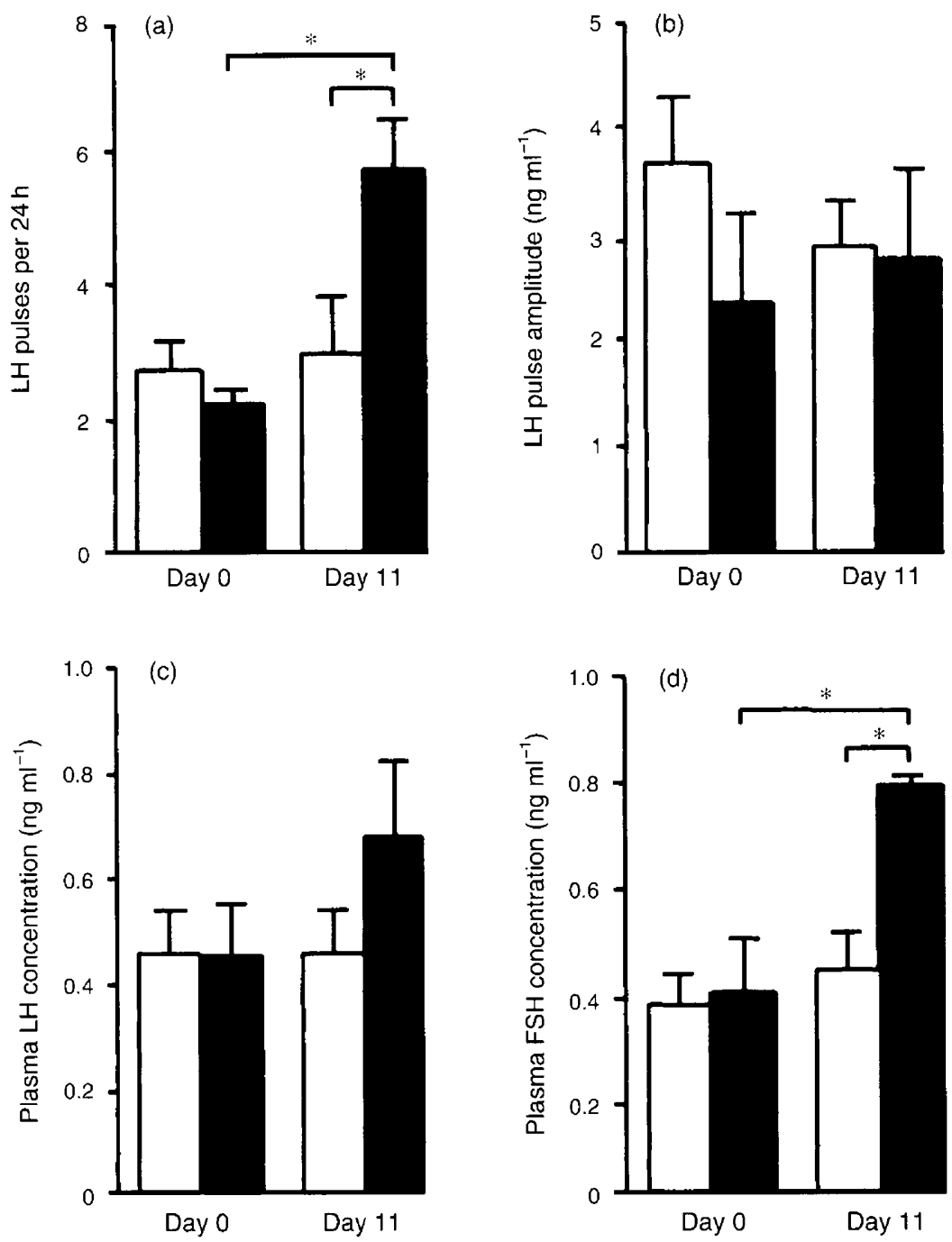

Fig. 1. LH pulse frequency, LH pulse amplitude, plasma LH concentration and plasma FSH concentration on day 0 and day 11 of male sheep offered a maintenance diet $(\square$, Group $M$ ) or a high protein and energy diet $(\mathbf{\square}$, Group $M+L$ ). Values are means \pm SFM. ${ }^{*}$ Significant at $P<0.05$.

$M+L$ relative to day $I$ and to Group $M(P<0.05)$, and glucose concentrations in CSF were higher in Group $\mathrm{M}+\mathrm{L}$ relative to Group $\mathrm{M}$.

There was no overall effect of interaction between time and diet, but there was a significant overall effect of diet on mean plasma concentrations of insulin $(P<0.05)$, and a significant overall effect of diet and time on mean CSF concentrations of insulin ( $P<0.05$; Fig. 3). On day 1 , plasma and CSF concentrations of insulin did not differ between the two groups. Insulin concentrations of plasma and CSF in Group $M+L$ were higher on day 3 relative to day 1 and to the values for Group $\mathrm{M}(P<0.05)$. On day 10 , insulin concentrations in CSF $(P<0.05)$ and plasma $(P=0.09)$ were higher in Group $M+L$ than in Group M. Concentrations of insulin were generally tenfold less in CSF than in plasma.

There was a significant overall effect of diet $(P<0.05)$, but not of time or the interaction between time and diet, on plasma concentrations of GH (Fig. 3). There was no overall effect of diet, time or the interaction between these factors, on mean
CSF concentrations of GH. On day 1, there were no differences between the two groups in plasma or CSF concentrations of $\mathrm{GH}$. On days 3 and 10, the plasma concentration of $\mathrm{GH}$ was lower in Group $\mathrm{M}+\mathrm{L}$ than in Group $\mathrm{M}(P<0.05)$, but CSF concentrations of $\mathrm{GH}$ did not differ between treatments. Concentrations of GH were generally threefold less in CSF than in plasma.

Overall, there was a significant effect of diet $(P<0.05)$, but not of time or the interaction between time and diet, on plasma concentrations of IGF-I (Fig. 3). There was no overall effect of diet, time or the interaction between the two, on CSF concentrations of IGF-I. On days 1 and 3, there were no differences between the two groups in plasma or CSF concentrations of IGF-I. By day 10, plasma IGF-I concentrations in Group $\mathrm{M}+\mathrm{L}$ had increased above those observed on day 1 and were higher than the values in Group $\mathrm{M}(P<0.05)$, but CSF concentrations of IGF-I did not differ between treatments. Concentrations of IGF-I in plasma were generally 15 -fold more than those in CSF. 

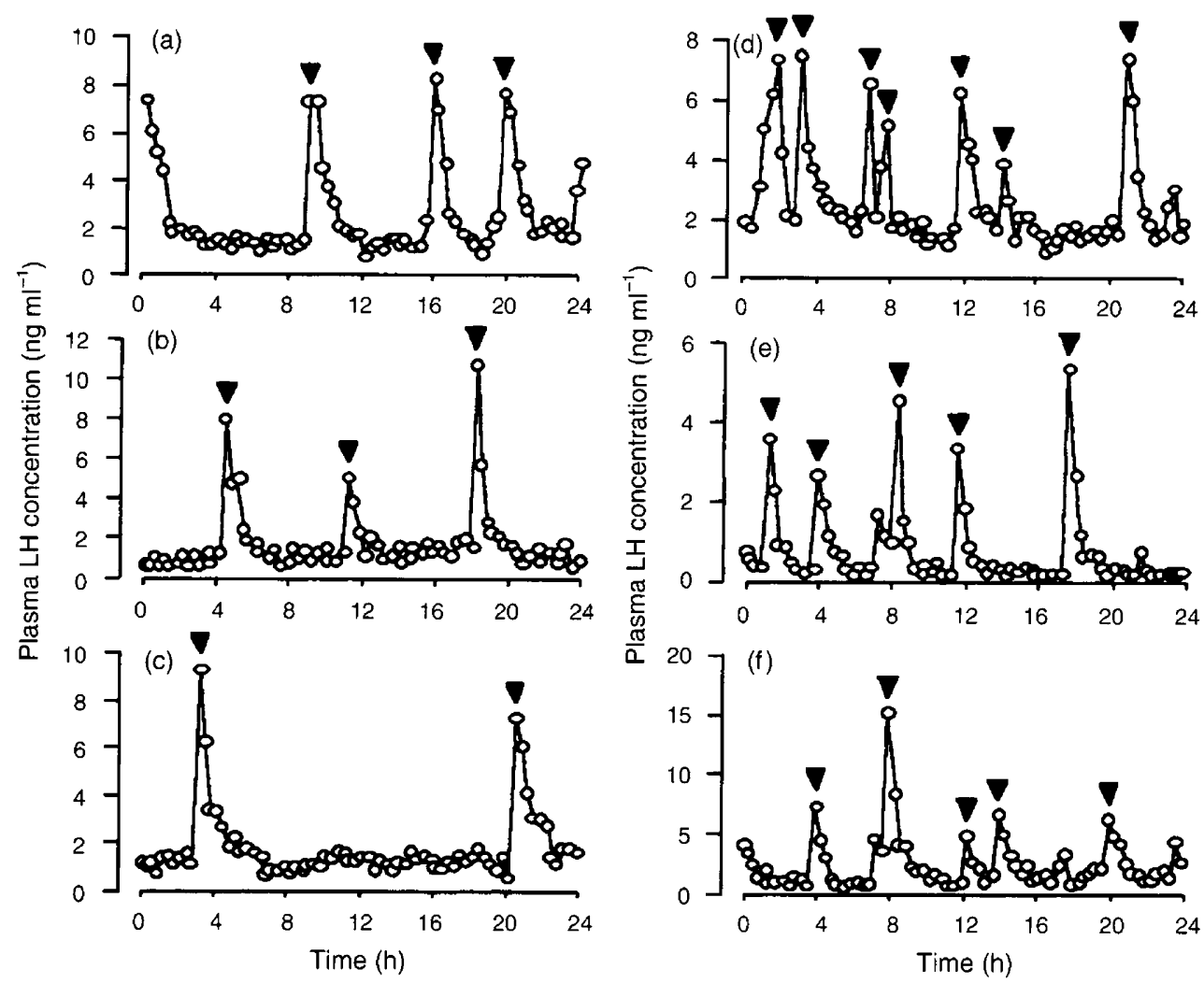

Fig. 2. Representative LH secretory profiles on day 11 of the dietary treatments of $(a-c)$ three male sheep offered a maintenance diet (Group $M$ ) and of $(d-f)$ three sheep offered a high protein and energy diet (Group $\mathrm{M}+\mathrm{L}$ ). Arrowheads represent pulses detected.

There was a significant overall effect of dietary treatment $(P<0.05)$, but not of time or the interaction between time and dietary treatment, on plasma concentrations of prolactin (Fig. 3). There was no overall effect of dietary treatment, time or the interaction between these factors, on CSF concentrations of prolactin. On day $I$, the dietary treatments had no effect on plasma concentrations of prolactin. On days 3 and 10, plasma prolactin concentrations in Group $\mathrm{M}+\mathrm{L}$ were higher relative to day $I$ values and to the values in Group $M(P<0.05)$. Concentrations of prolactin in CSF were generally tenfold less than those in plasma.

Over the 10 days, the dietary treatments had no effect on plasma or CSF concentrations of free tri-iodothyronine, thyroxine or cortisol (data not shown). The concentrations of free tri-iodothyronine and thyroxine in CSF were 20-30-fold lower and the concentration of cortisol in CSF was fourfold lower than that in plasma.

On day 10, there was no effect of dietary treatments on plasma or CSF concentrations of palmitic, stearic, arachidic, palmitoleic or linolenic acids (Table 1). The concentrations of oleic acid in CSF, but not plasma, decreased threefold $(P<0.05)$ in Group $\mathrm{M}+\mathrm{L}$, and plasma concentrations of linoleic acid showed a $30 \%$ increase $(P<0.05)$ in Group $M+L$ over the course of the experiment. Concentrations of linoleic acid in CSF were below the limit of detection of the assay. Concentrations of palmitic, stearic and oleic acid in CSF were 20 -fold, fourfold and 25-fold, respectively, less than those in plasma. Concentrations of arachidic acid in CSF were similar to those in plasma.
Over the 10 days, the dietary treatments had no effect on plasma or CSF concentrations of glutamate, histidine or tryptophan (data not shown). In plasma, there was a significant overall effect of diet $(P<0.05)$, and the interaction between diet and time $(P<0.05)$ on the concentrations of phosphoserine, arginine, tyrosine, valine and phenylalanine (Table 2). On day I, plasma concentrations in Groups $\mathrm{M}$ and $\mathrm{M}+\mathrm{L}$ were similar, except for valine, glycine + asparagine and leucine, which were higher in Group $\mathrm{M}(P<0.05)$. On day 3, plasma concentrations of glutamine were higher in Group $\mathrm{M}+\mathrm{L}$ and aspartate, glycine + asparagine and leucine were higher in Group M $(P<0.05)$. On day 10, plasma concentrations of phosphoserine, aspartate, serine, arginine, proline, tyrosine, methionine and phenylalanine were higher in Group $\mathrm{M}+\mathrm{L}$ $(P<0.05)$. There was no effect of treatment, or time, on the ratio of plasma tryptophan or tyrosine to the other large neutral amino acids (that is, to phenylalanine, valine, leucine and isoleucine).

There were significant effects of diet $(P<0.05)$ and of the interaction between diet and time $(P<0.05)$, on the concentrations of phosphoserine, serine, glutamine, GABA, threonine, arginine, tyrosine, valine and phenylalanine in CSF (Table 3). There was also a significant effect of treatment on the concentrations of alanine, proline and isoleucine $(P<0.05)$. On day 1 , the concentrations of phosphoserine, aspartate, glutamine, taurine, GABA and alanine were higher in Group $M+L$, and methionine concentrations were lower in Group $M+L(P<0.05)$. On day 3 , the concentrations of aspartate, glutamine, GABA, threonine, alanine, arginine, tyrosine, 
Plasma
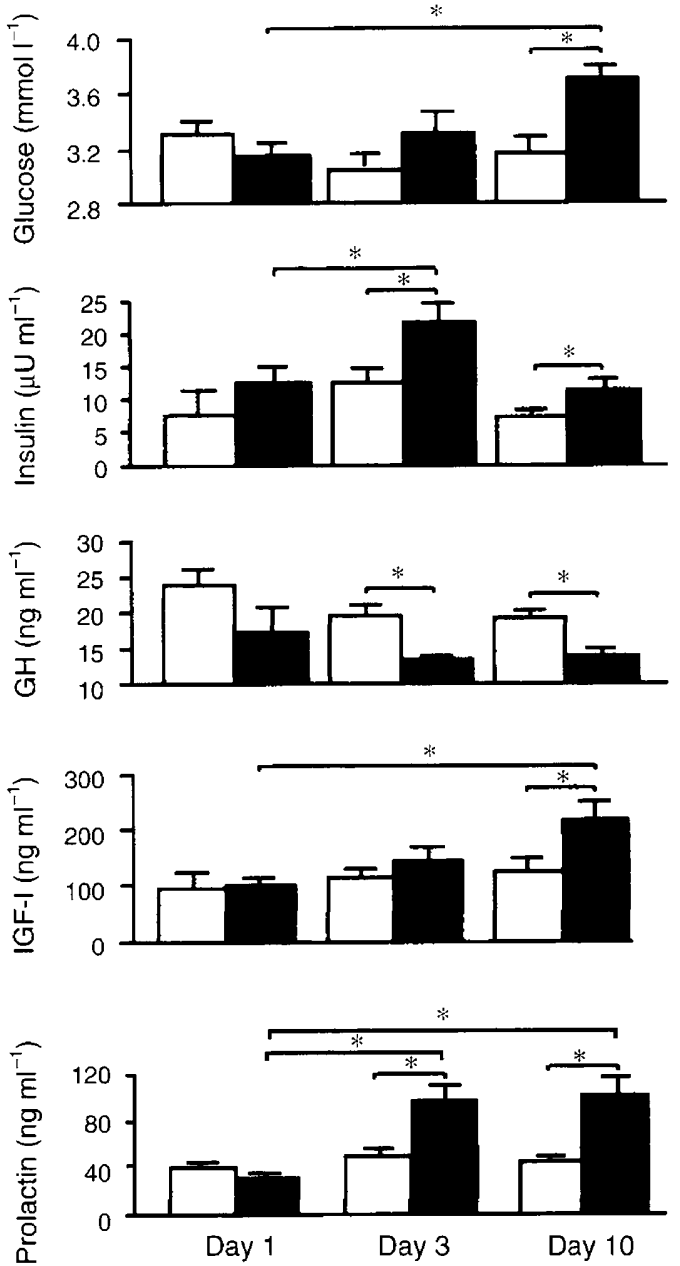

CSF
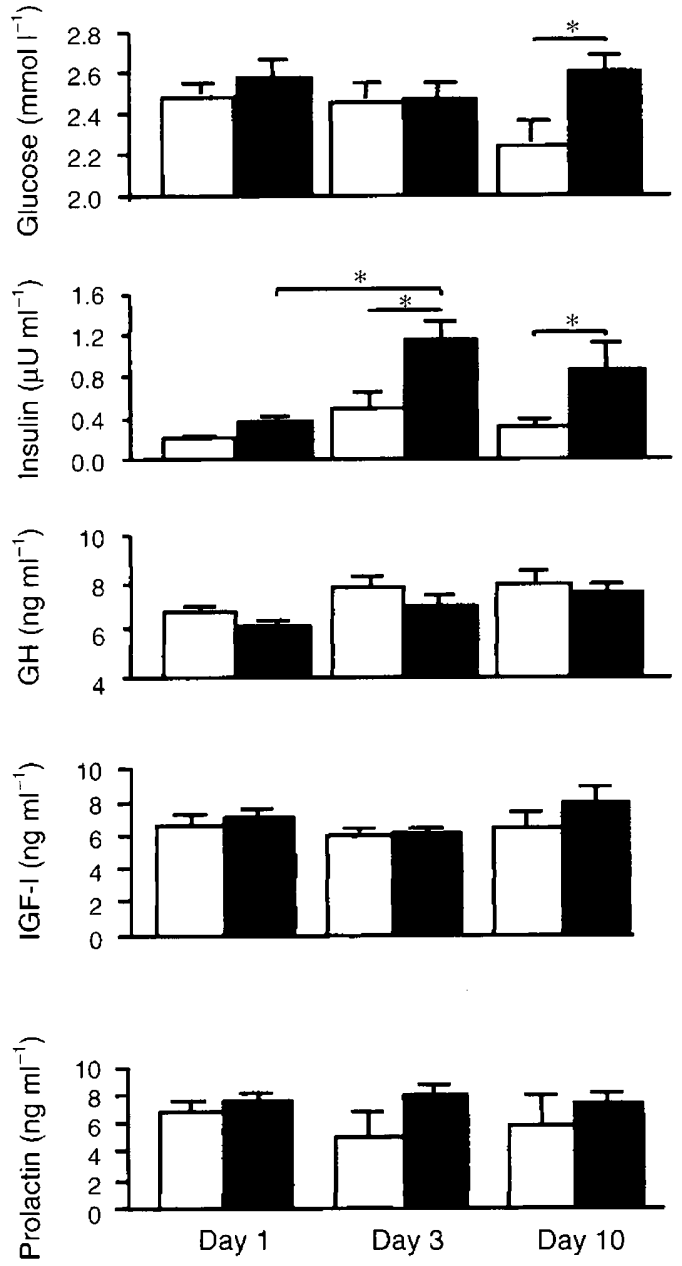

Fig. 3. Concentrations on days 1,3 and 10 of glucose, insulin, GH, insulin-like growth factor I (IGF-I) and prolactin in plasma and cerebrospinal fluid (CSF) of male sheep offered a maintenance diet ( $\square$, Group $M$ ) or a high protein and energy $\operatorname{diet}\left(\boldsymbol{\square}\right.$, Group $M+L$ ). Values are means \pm SEM. ${ }^{*}$ Significant at $P<0.05$.

cystine and phenylalanine were higher in Group $M+L$ than in Group $M(P<0.05)$. On day 10, the concentrations of phosphoserine, glutamine, GABA, threonine, alanine, arginine, proline, tyrosine, valine, methionine, isoleucine and phenylalanine were higher in Group $\mathrm{M}+\mathrm{L}$ than in Group $\mathrm{M}$ $(P<0.05)$.

\section{Discussion}

Nutritional supplements increased LH pulse frequency and mean FSH concentrations, a finding supported by previous studies in mature male sheep by our group (for review see Martin et al, 1994). The LH pulse amplitude and mean LH concentrations were not affected, reinforcing the postulate that the nutritional effects are exerted on the GnRH neurones in the hypothalamus. In addition, the results presented here show that concomitant with the increase in gonadotrophin secretion, there is an increase in CSF concentrations of insulin, glucose and certain amino acids. These findings are consistent with the concept put forward by Wade and Schneider (1992) that circulating factors that reflect nutritional status can reach the central nervous system and affect the GnRH pulse generator.

Otani et al. (1983), in a similar study to the present one, observed the effects of a nutritional treatment on plasma and CSF concentrations of various humoral substances in sheep. They were unable to demonstrate any effects of diet on CSF concentrations of glucose or insulin. However, in their study, plasma and CSF samples were only taken over $3 \mathrm{~h}$, during a single meal. In the present study, the effects of diet on CSF concentrations of metabolic substances on day 1 of the dietary treatments were similarly undetectable, and significant differences were not observed until 3 days after the start of the dietary treatments. This delay supports the postulate by Bronson and Manning (1988) that, if the putative pathway affecting gonadotrophin secretion does indeed arise directly from the metabolic state of the animal, then it must have a time-averaging dimension that damps out momentary fluctuations in food intake and energy expenditure.

The increase in concentrations of amino acids in CSF observed in the animals on the high diet was not always 
Table 1. Concentrations of long-chain free fatty acids in plasma and cerebrospinal fluid (CSF) of male sheep after 10 days of a maintenance diet (Group $M$ ) or of a high protein and energy diet (Group $M+L$ )

\begin{tabular}{|c|c|c|c|c|c|c|c|}
\hline Plasma (ng ml $\mathrm{ml}^{-1}$ ) & $198.0 \pm 38.6^{\mathrm{a}}$ & $20.0 \pm 9.0^{a}$ & $313.0 \pm 27.0^{a}$ & $329.0 \pm 74.0^{a}$ & $157.0 \pm 34.0^{a}$ & $50.8 \pm 10.8^{a}$ & $169.0 \pm 22.0^{a}$ \\
\hline $\mathrm{CSF}\left(\mathrm{ng} \mathrm{ml} \mathrm{l}^{-1}\right.$ ) & $9.6 \pm 1.9^{a}$ & ND & $83.3 \pm 13.3^{a}$ & $13.3 \pm 2.7^{\mathrm{a}}$ & ND & ND & $187.0 \pm 38.0^{\alpha}$ \\
\hline $\mathrm{CSF}\left(\mathrm{ng} \mathrm{ml} \mathrm{m}^{-\mathrm{I}}\right.$ ) & $11.1 \pm 2.1^{\mathrm{a}}$ & ND & $50.7 \pm 19.3^{a}$ & $4.3 \pm 2.8^{\mathrm{b}}$ & ND & ND & $211.0 \pm 25.0^{\mathrm{a}}$ \\
\hline
\end{tabular}

Values are means \pm SEM.

Values with different superscripts significant at $P<0.05 . \mathrm{ND}=$ not-detectable.

Table 2. Concentrations of amino acids on days 1,3 and 10 in the plasma of male sheep offered a maintenance diet (Group M) or a high protein and energy diet (Group $M+L$ )

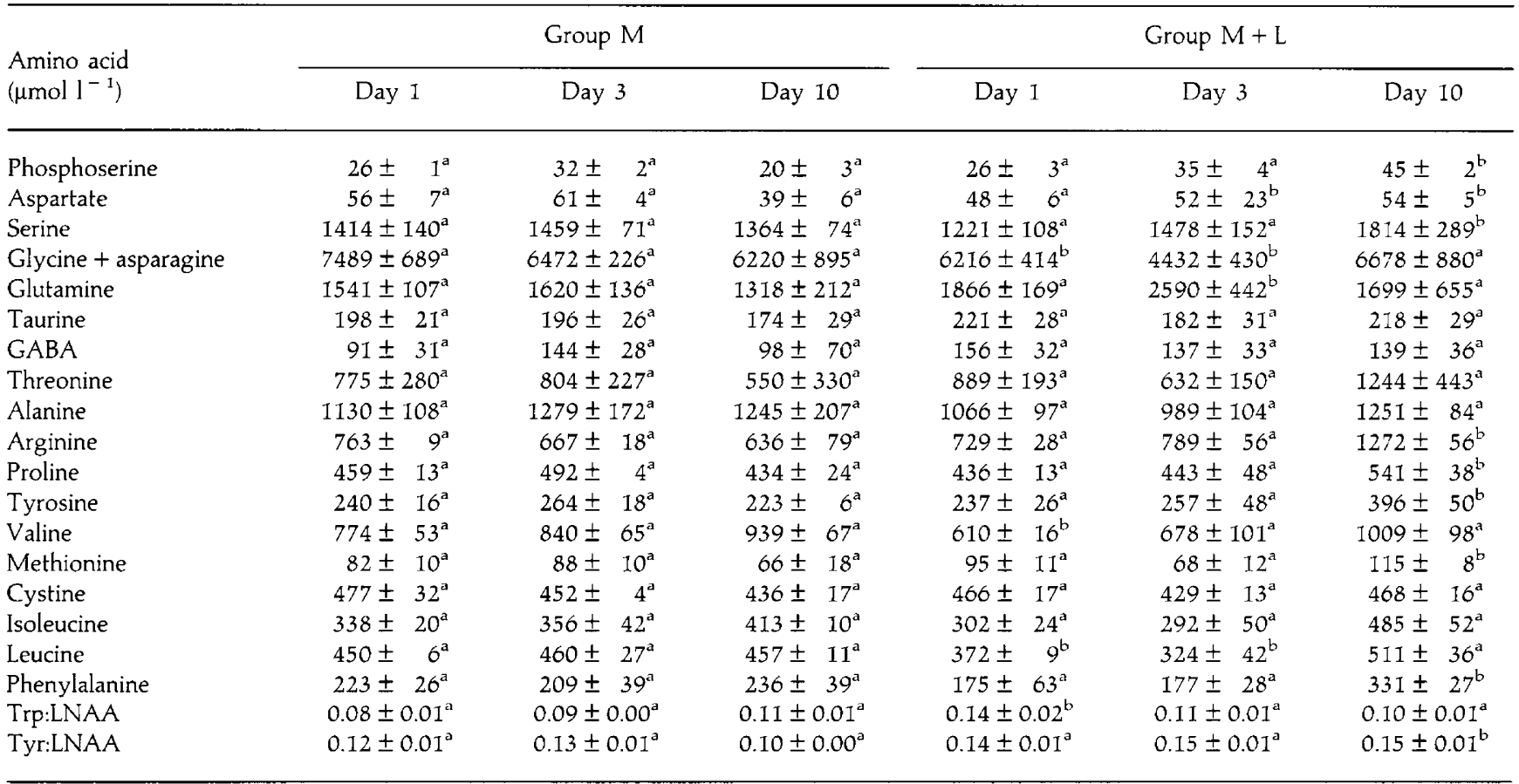

GABA, $\gamma$-aminobutyric acid; LNAA, large neutral amino acids; Trp:LNAA, ratio of tryptophan to the LNAAs; Tyr:LNAA, ratio of tyrosine to the LNAAs. Values are means \pm SEM. Different superscripts indicate a significant difference between treatments on the same day $(P<0.05)$.

accompanied by a concomitant increase in plasma concentrations. This finding may be related to the existence of an active transport system for certain substances at the bloodbrain barrier (Davson et al., 1987) and highlights the problem that when investigating possible central metabolic signals, candidates may not be predicted by measuring their concentrations in peripheral blood. Concentrations of phosphoserine, glutamine, GABA, threonine, alanine, arginine, proline, tyrosine, valine, isoleucine and phenylalanine were higher in the CSF of the lupin-supplemented rams, whereas only phosphoserine, arginine, tyrosine, valine and phenylalanine were higher in the plasma of these rams. It has been shown that the secretion of $\mathrm{GnRH}$ is controlled by monoaminergic neurotrans- mitters (Thiéry and Martin, 1991), the turnover of which are affected by the availability of precursors obtained from the diet (Fernstrom, 1983, 1990). Phenylalanine, tyrosine and tryptophan, precursors for catecholamines and indolamines, are particularly important. These amino acids may be important links in the mechanism by which nutrition influences reproduction (Riggs and Malven, 1974; Meyer and Goodman, 1985). There is also some evidence that infusion of amino acids can stimulate the release of LH in undernourished ewes (Bucholtz et al., 1988). The excitatory amino acids (for example, glutamate, lysine, alanine and GABA) have also been shown to influence the pulsatile discharge of LH and GnRH (Ondo, 1974; Donoso et al., 1992; Lopez et al., 1992; Bonavera et al., 1993). 
Table 3. Concentrations of amino acids on days 1, 3 and 10 in the cerebrospinal fluid of male sheep offered a maintenance diet (Group $M$ ) or a high protein and energy diet (Group $M+L$ )

\begin{tabular}{|c|c|c|c|c|c|c|}
\hline \multirow{2}{*}{$\begin{array}{l}\text { Amino acid } \\
\left(\mu \mathrm{mol} \mathrm{I}^{-1}\right)\end{array}$} & \multicolumn{3}{|c|}{ Group M } & \multicolumn{3}{|c|}{ Group $M+L$} \\
\hline & Day 1 & Day 3 & Day 10 & Day 1 & Day 3 & Day 10 \\
\hline Aspartate & $15 \pm 1^{a}$ & $16 \pm 5^{a}$ & $17 \pm \quad 5^{a}$ & $21 \pm 3^{b}$ & $29 \pm 3^{\mathrm{b}}$ & $25 \pm 3^{\mathrm{a}}$ \\
\hline Serine & $50 \pm 9^{a}$ & $50 \pm 13^{\mathrm{a}}$ & $37 \pm \quad 6^{a}$ & $39 \pm 5^{a}$ & $55 \pm 14^{\mathrm{a}}$ & $72 \pm 14^{a}$ \\
\hline Taurine & $40 \pm 7^{\mathrm{a}}$ & $48 \pm 2^{a}$ & $43 \pm 3^{a}$ & $63 \pm 9^{b}$ & $34 \pm 13^{a}$ & $54 \pm 15^{\mathrm{a}}$ \\
\hline GABA & $226 \pm 77^{a}$ & $332 \pm 23^{\mathrm{a}}$ & $287 \pm 41^{a}$ & $371 \pm 24^{b}$ & $550 \pm 132^{b}$ & $387 \pm 20^{\mathrm{b}}$ \\
\hline Threonine & $72 \pm 16^{a}$ & $110 \pm 12^{a}$ & $62 \pm 10^{a}$ & $91 \pm 9^{a}$ & $267 \pm 24^{b}$ & $190 \pm 12^{b}$ \\
\hline Alanine & $69 \pm 13^{\mathrm{a}}$ & $128 \pm 6^{a}$ & $98 \pm 9^{a}$ & $109 \pm 12^{b}$ & $212 \pm 15^{c}$ & $130 \pm 17^{\mathrm{b}}$ \\
\hline Arginine & $119 \pm 17^{\mathrm{a}}$ & $102 \pm 13^{a}$ & $94 \pm 14^{a}$ & $122 \pm 15^{\mathrm{a}}$ & $137 \pm 15^{b}$ & $166 \pm 10^{b}$ \\
\hline Proline & $21 \pm 2^{a}$ & $65 \pm 13^{a}$ & $18 \pm 4^{\mathrm{a}}$ & $23 \pm 2^{a}$ & $49 \pm 10^{a}$ & $42 \pm 3^{b}$ \\
\hline Isoleucine & $11 \pm 2^{a}$ & $13 \pm$ & $10 \pm \quad I^{a}$ & $8 \pm 1^{\mathrm{a}}$ & $15 \pm$ & $14 \pm$ \\
\hline Leucine & $25 \pm 3^{a}$ & $31 \pm$ & $23 \pm$ & $22 \pm 3^{a}$ & $35 \pm$ & $29 \pm$ \\
\hline Phenylalanine & $25 \pm 5^{a}$ & $24 \pm$ & $23 \pm$ & $29 \pm 2^{a}$ & $42 \pm$ & $37 \pm$ \\
\hline
\end{tabular}

GABA: $\gamma$-aminobutyric acid.

Values are means \pm SEM. Different superscripts indicate a significant difference between treatments on the same day $(P<0.05)$.

The evidence from the present study, along with the previous studies described above, offers various pathways by which nutrition may alter $\mathrm{LH}$ secretion through dietary amino acids. These pathways need to be investigated in more detail.

Also associated with the nutrition-stimulated increase in gonadotrophin secretion was an increase in the concentration of insulin in plasma and CSF. The central action of insulin on the GnRH neurones is supported by numerous findings, for example the central infusion of insulin increases $\mathrm{LH}$ secretion in sheep (Miller et al., 1995) and the electrical activity of basal hypothalamic neurons in rats (Oomura, 1976). In addition, the presence of insulin receptors in the arcuate nucleus and median eminence within the medial basal hypothalamus in rats (van Houten et al., 1980) suggests that insulin acts directly on the GnRH neurones located in the same areas (Lehman et al., 1986). The pathways involving insulin described above, together with the results of the present study which indicate that fluctuations in central insulin concentrations are associated with nutritional status, provide the impetus to examine further the possibility that insulin is a critical link in the nutritional control of gonadotrophin secretion. This impetus is particularly strong when previous findings by our group, that intracerebroventricular infusion of insulin, providing concentrations similar to those observed in CSF in the present study, stimulated LH secretion in male sheep (Miller et al., 1995), are taken into account.

In the present study, glucose concentrations in CSF were also higher in the nutrition-supplemented group on day 10 of treatment, although this was due more to a decline in glucose concentrations in the maintenance-fed animals on that day. Nevertheless, glucose may be an essential nutrient for $\mathrm{LH}$ release in rats and sheep (Sen et al., 1979; Clarke et al., 1990;
Bucholtz et al., 1996). However, intravenous and central infusions of glucose do not increase LH secretion in sheep (Boukhliq et al., 1991; Miller et al., 1995), suggesting that either glucose is not involved in the nutritional stimulation of the GnRH pulse generator, or that it may be a non-limiting factor for insulin action. This last point is supported by the finding that, in perifused hypothalamic fragments, GnRH release is markedly increased by low concentrations of insulin, but only when glucose is available (Arias et al., 1992).

The sheep offered the nutritional supplement also had an increase in peripheral concentrations of linoleic acid and a decrease in concentrations of oleic acid in CSF. Richards et al. (1989) and Canfield and Butler (1991), working with cows, and Estienne et al. (1989, 1990) working with sheep, have suggested that increased circulating concentrations of free fatty acids impair reproductive activity. It is difficult to compare fluctuations in concentrations of individual fatty acids, such as linoleic acid in plasma and oleic acid in CSF, with the total free fatty acid concentrations described in the above studies. However, linoleic and oleic acids have been shown to influence the permeability of the blood-brain barrier to humoral substrates (Sztriha and Betz, 1991). Therefore, dietary fluctuations in the concentrations of individual fatty acids in plasma or CSF may influence the diffusion of other metabolic signals across the blood-brain barrier and, hence, may be involved indirectly in the nutritional stimulation of gonadotrophin secretion.

An increase in peripheral concentrations of IGF-I and a decrease in peripheral GH concentrations in the nutritionsupplemented rams was observed in the present study. However, concentrations of GH and IGF-I in CSF were not affected by the dietary treatments. Although IGF-I has been suggested as a putative link between nutrition and reproduction in 
females (Monget and Martin, 1997), and there is evidence of IGF-I receptors in the rat brain (Werther et al., 1989), it is unlikely that IGF-I and GH are candidates for a pathway through which nutrition affects gonadotrophin secretion, as differences reflecting the nutritional status of the ram should be detectable in the brain. However, the effect of nutrition on the IGF-binding proteins was not investigated in the present study and, thus, the involvement of the IGF system in the nutritional stimulation of gonadotrophin secretion needs further study.

Although there is some evidence that prolactin (UvnäsMoberg et al., 1985; Armstrong et al., 1986; Tjondronegoro et al., 1992), cortisol (Dubey et al., 1986; Cameron et al., 1993) and the thyroid hormones (Chandrasekhar et al., 1985) are involved in the metabolic modulation of gonadotrophin secretion, the lack of response in the central nervous sytem in the present study indicates that these hormones are unlikely candidates for a CSF-borne nutritional signal that affects the activity of the GnRH pulse generator. In addition, the finding that nutrition does not affect other centrally controlled endocrine systems, like the adrenal or thyroid axes, indicates that the effect of nutrition on $\mathrm{GnRH}$ secretion is a highly specific one.

The present study has demonstrated that nutritional stimulation of gonadotrophin secretion is accompanied by fluctuations in plasma and CSF concentrations of insulin, glucose and certain amino acids in adult male sheep. These correlated changes indicate that metabolic fluctuations may be monitored by the brain and be part of the critical link between the control systems regulating metabolic status and the reproductive axis. However, the possibility still remains that the increases in CSF concentrations of glucose, insulin and amino acids were coincidental with the gonadotrophin responses and did not have a causal relationship, that is, the metabolic differences detected in the CSF are not the signals that the GnRH pulse generator interprets in responding to nutrition. For example, it has been suggested that there are glucoreceptors in the liver (Russek, 1963), and that these receptors monitor blood glucose concentrations and send signals to the central nervous system through vagal afferents to regulate food intake. It is possible that an hepatic-vagal-central nervous system pathway is involved in the nutritional regulation of gonadotrophin secretion if a theoretical framework from the field of metabolic control of food intake is used. There is some evidence for this postulate in a study by Cagampang et al. (1992) that indicated that some mechanism involving the afferent vagal nerves, particularly the gastric vagus, has a major role in the suppression of pulsatile LH release during acute fasting in rats. The result of Miller et al. (1995), that showed that intracerebroventricular infusion of insulin-stimulated LH secretion in male sheep, is a partial response to the postulate that the GnRH pulse generator does not respond to CSF-borne signals. However, the possibility of alternative pathways by which metabolic signals communicate with the GnRH neuronal network still requires further investigation.

In conclusion, the present data demonstrate that adult male sheep can be a valuable model to study the control of the gonadotrophic axis by nutrition by the central nervous system and suggests that the possible roles of insulin, glucose, amino acids and other metabolic signals as modulators of $\mathrm{GnRH}$ secretion should be examined further. In addition, as mal- nutrition can limit the reproductive activity of animals and humans, further studies are required to determine whether inhibition of reproductive activity involves different central pathways to those investigated in the present study using nutritional supplementation as a model.

The work described in this paper would not have been feasible without the technical support and expertise of many people, particularly M. Blackberry, J. Fisher, S. Walkden-Brown and J. Beesley. The authors are grateful to the National Institute of Diabetes, Digestive and Kidney Disease, the Center for Population Research of the National Institute of Child Health, the Agricultural Research Service of the U.S. Department of Agriculture, and the University of Maryland School of Medicine for the reagents for the prolactin, GH and FSH assays. The reagents for the insulin assay were kindly provided by $P$. Wynn (Department of Animal Science, Sydney University, NSW). This work was funded by the Australian Research Council and the CSIRO Division of Animal Production which is supported by the International Wool Secretariat.

\section{References}

Abraham GE, Buster JE and Teller RC (1972) Radioimmunoassay of plasma cortisol Analytical Letters 5 757-765

Arias P, Rodriguez M, Szwarcfarb B, Sinay IR and Moguilevsky JA (1992) Effect of insulin on LHRH release by perifused hypothalamic fragments Neuroendocrinology 56 415-418

Armstrong JD, Britt JH and Kraeling RR (1986) Effect of restriction of energy during lactation on body condition, energy metabolism endocrine changes and reproductive performance in primiparous sows Journal of Animal Science 63 1915-1925

Atkinson S and Adams NR (1988) Adrenal glands alter the concentration of oestradiol- $17 \beta$ and its receptor in the uterus of ovariectomized ewes Journal of Endocrinology 118 375-380

Bergmeyer HU and Bern't E (1974) D-Glucose: determination with glucose oxidase and peroxidase. In Methods of Enzymatic Analysis pp 1205-1215 Ed. HU Bergmeyer. Academic Press, New York

Bonavera J, Kalra SP and Kalra PS (1993) Inhibitory brain peptides $\beta$-endorphin ( $\beta$-END), neuropeptide $K(N P K$ ) and interleukin-I $\beta$ (IL-1 $\beta$ ) enhance pituitary LH response to excitatory amino acids Journal of Reproduction and Fertility Abstract Series 11 Abstract 38

Boukhliq R, Martin GB and Adams NR (1991) Glucose infusion does not alter gonadotrophin levels in the ram Proceedings of the Australian Society for Reproductive Biology 2389

Breier BH, Gallaher BW and Gluckman PD (1991) Radioimmunoassay for insulin-like growth factor-1: solutions to some potential problems and pitfalls Journal of Endocrinology 128 347-357

Bronson FH and Manning J (1988) Food, energy expenditure and puberty in female rats Proceedings of the Eleventh International Congress on Animal Reproduction and Artificial Insemination (Dublin) 5 109-116

Bucholtz DC, Vannerson LA, Ebling FJP, Wood RI, Suttie JM and Foster DL (1988) Modulation of gonadotrophin secretion in growth-restricted lambs by glucose-amino acids Biology of Reproduction 38 (Supplement 1) 185

Bucholtz DC, Vidwans NM, Herbosa CG, Schillo KK and Foster DL (1996) Metabolic interfaces between growth and reproduction. V. Pulsatile luteinizing hormone secretion is dependent on glucose availability Endocrinology $137601-607$

Cagampang FRA, Maeda K and Ota K (1992) Involvement of the gastric vagal nerve in the suppression of pulsatile luteinizing-hormone release during acute fasting in rats Endocrinology $1303003-3006$

Cameron JL, Koerker DJ and Steiner RA (1985) Metabolic changes during maturation of male monkeys: possible signals for onset of puberty American Journal of Physiology 249 E385-E391

Cameron JL, Helmreich DL and Schreihofer DA (1993) Modulation of reproductive hormone secretion by nutritional intake: stress signals versus metabolic signals Human Reproduction 8 (Supplement 2) 162-167

Canfield RW and Butler WR (1991) Energy balance, first ovulation and the effects of naloxone on LH secretion in early postpartum dairy cows journal of Animal Science 69 740-746 
Chandrasekhar Y, Holland MK, d'Occhio MJ and Setchell BP (1985) Spermatogenesis, seminal characteristics and reproductive hormone levels in mature rams with induced hypothyroidism and hyperthyroidism Journal of Endocrinology 105 39-46

Clarke IJ, Horton RJE and Doughton BW (1990) Investigation of the mechanism by which insulin-induced hypoglycemia decreases luteinizing hormone secretion in ovariectomized ewes Endocrinology 127 1470-1476

Cohen SA and Strydom DJ (1988) Amino acid analysis utilizing phenylisothiocyanate derivatives Analytical Biochemistry 174 1-16

Davson H, Welch K and Segal MB (1987) Physiology and Pathophysiology of the Cerebrospinal Fluid pp 485-521. Churchill Livingstone, London

Donoso AO, Lopez FJ and Negro-Vilar A (1992) Cross-talk between excitatory and inhibitory amino acids in the regulation of luteinizing hormone-releasing hormone secretion Endocrinology 131 1559-1561

Downing JA, Joss J, Connell P and Scaramuzzi RJ (1995) Ovulation rate and the concentrations of gonadotrophic and metabolic hormones in ewes fed lupin grain Journal of Reproduction and Fertility 103 137-145

Dubey AK, Cameron JL, Steiner RA and Plant TM (1986) Inhibition of gonadotropin secretion in castrated rhesus monkeys (Macaca mulatta) induced by dietary restriction: analogy with the pubertal hiatus of gonadotropin release Endocrinology 118 518-525

Estienne MJ, Schillo KK, Green MA and Boling JA (1989) Free fatty acids suppress growth hormone, but not luteinizing hormone, secretion in sheep Endocrinology 125 85-91

Estienne MJ, Schillo KK, Hileman SM, Green MA, Hayes SH and Boling JA (1990) Effects of free fatty acids on luteinizing hormone secretion in ovariectomized lambs Endocrinology 126 1934-1940

Fernstrom JD (1983) Role of precursor availability in control of monoamine biosynthesis in brain Physiological Reviews 63 484-546

Fernstrom JD (1990) Aromatic amino acid monoamine synthesis in the central nervous system: influence of the diet Journal of Nutrition and Biochemistry 1 508-517

Forbes JM (1974) Feeding in sheep modified by intraventricular estradiol and progesterone Physiology and Behavior 12 741-747

Foster DL and Olster DH (1985) Effect of restricted nutrition on puberty in the lamb: patterns of tonic luteinizing hormone (LH) secretion and competency of the LH surge system Endocrinology $116375-381$

Gluckman PD, Johnson-Barrett JJ, Butler JH, Edgar BW and Gunn TR (1983) Studies on insulin-like growth factor-1 and -ll by specific radioligand assays in umbilical cord blood Clinical Endocrinology 19 405-413

Lehman MN, Robinson JE, Karsch FJ and Silverman AJ (1986) Immunocytochemical localization of luteinizing hormone-releasing hormone (LHRH) pathways in the sheep brain during anestrus and the mid-luteal phase of the estrous cycle Journal of Comparative Neurology 244 19-35

Lopez FJ, Donoso AO and Negro-Vilar A (1992) Endogenous excitatory amino acids and glutamate receptor subtypes involved in the control of hypothalamic LHRH secretion Endocrinology 130 1986-1992

McDonald P, Edwards RA and Greenhalgh JFD (1991) Nutritive value of feedstuffs. In Animal Nutrition 4th Edn pp 572-577. John Wiley and Sons, New York

Martin GB, Oldham CM and Lindsay DR (1980) Increased plasma LH levels in seasonally anovular Merino ewes following the introduction of rams Animal Reproduction Science 3 125-132

Martin GB, Walkden-Brown SW, Boukhliq R, Tjondronegoro S, Miller DW, Fisher IS, Hötzel MJ, Restall BJ and Adams NR (1994) Non-photoperiodic inputs into seasonal breeding in male ruminants. In Perspectives in Comparative Endocrinology pp 574-585 Eds KG Davey, RE Peter and SS Tobe. National Research Council, Ottawa

Meyer SL and Goodman RL (1985) Neurotransmitters involved in mediating the steroid-dependent suppression of pulsatile luteinizing hormone secretion in anestrous ewes: effects of receptor antagonists Endocrinology 116 2054-2061

Miller DW, Blache D and Martin GB (1995) The role of intracerebral insulin in the effect of nutrition on gonadotrophin secretion in mature male sheep Journal of Endocrinology 147 321-329

Monget P and Martin GB (1997) Involvement of insulin-like growth factors in the interactions between nutrition and reproduction in female mammals Human Reproduction 12 (Supplement I) 33-52
Ondo JG (1974) Gamma-aminobutyric acid effects on pituitary gonadotropin secretion Science 186 738-739

Oomura Y (1976) Significance of glucose, insulin, and free fatty acids on the hypothalamus feeding and satiety neurons. In Hunger: Basic Mechanisms and Clinical Implications pp 145-157 Eds D Novin, W Wyrwicka and G Bray. Raven Press, New York

Otani F, Takahashi H, Ambo K and Tsuda T (1983) Changes of blood and cerebrospinal fluid constituents after feeding in sheep Tohoku Journal of Agricultural Research 33 155-163

Pappenheimer JR, Heisey SR, Jordan EF and Downer JDC (1962) Perfusion of the cerebral ventricular system in unanesthetized goats American Journal of Physiology 203 763-774

Petterson DS and Mackintosh JB (1994) The chemical composition and nutritive value of Australian grain legumes Grains Research and Development Corporation Report, Canberra, Australia

Richards MW, Wettemann RP and Schoenemann HM (1989) Nutritional anestrus in beef cows: concentrations of glucose and nonesterified fatty acids in plasma and insulin in serum Journal of Animal Science $672354-2362$

Riggs BL and Malven PV (1974) Effects of intraventricular infusion of serotonin, norepinephrine, and dopamine on spontaneous LH release in castrate male sheep Biology of Reproduction 11 587-592

Robitaille L and Hoffer LJ (1988) Measurement of branched chain amino acids in blood plasma by high performance liquid chromatography Canadian Journal of Physiology and Pharmacology 66 613-617

Russek M (1963) Participation of hepatic glucoreceptors in the control of intake of food Nature 197 79-80

Sen KK, Azhar S and Menon KMJ (1979) Evidence for the involvement of an energy-dependent process in gonadotropin-releasing hormone-stimulated luteinizing hormone release by rat anterior pituitary Endocrinology 105 1158-1161

Sisk CL and Bronson FH (1986) Effects of food restriction and restoration on gonadotropin and growth hormone secretion in immature male rats Biology of Reproduction 35 554-561

Sukhija PS and Palmquist DL (1988) Rapid method for determination of total fatty acid content and composition of feedstuffs and faeces Journal of Agricultural and Food Chemistry 36 1202-1206

Sztriha L and Betz AL (1991) Oleic acid reversibly opens the blood-brain barrier Brain Research 550 257-262

Thiéry J-C and Martin GB (1991) Neurophysiological control of the secretion of gonadotropin-releasing hormone and luteinizing hormone in the sheep - a review Reproduction, Fertility and Development 3 137-173

Tindal JS, Knaggs GS, Hart IC and Blake LA (1978) Release of growth hormone in lactating and non-lactating goats in relation to behaviour, stages of sleep, electroencephalographs, environmental stimuli and levels of prolactin, insulin, glucose and free fatty acids in the circulation Journal of Endocrinology $\mathbf{7 6}$ 333-346

Tjondronegoro S, Miller DW, Martin GB and Adams NR (1992) Prolactin secretion in the male sheep: effect of nutritional status and testicular hormones Proceedings of the 9th International Congress on Endocrinology pp 265. Nice, France

Uvnäs-Moberg $K$, Stock $S$, Eriksson $M$, Lindén $A$, Einarsson $S$ and Kunavongkrit A (1985) Plasma levels of oxytocin increase in response to suckling and feeding in dogs and sows Acta Physiologica Scandinavica 124 391-398

van Houten M, Posner BI, Kopriwa BM and Brawer JR (1980) Insulin binding sites localized to nerve terminals in rat median eminence and arcuate nucleus Science 207 1081-1083

Wade GN and Schneider JE (1992) Metabolic fuels and reproduction in female mammals Neuroscience and Biobehavioral Reviews 16 235-272

Werther GA, Hogg A, Oldfield BJ, McKinley MJ, Figdor R and Mendelsohn FAO (1989) Localisation and characterisation of IGF-I receptors in rat brain and pituitary gland using in vitro autoradiography and computerised densitometry - a distinct distribution Journal of Neuroendocrinology 1369 377

Williams NI and Cameron JL (1996) Stimulation of luteinizing hormone (LH) secretion in male rhesus monkeys by food intake: role of circulating triiodothyronine (T3) Proceedings of the 10th International Congress of Endocrinology pp 531. San Francisco, USA 